\title{
əVariability and Drivers of Ocean Temperature Extremes in a Warming Western Boundary Current
}

\author{
Junde Li, ${ }^{\mathrm{a}}$ MONinya Roughan, ${ }^{\mathrm{a}}$ AND COLETTE KerRY ${ }^{\mathrm{a}}$

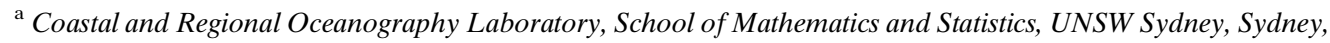 \\ New South Wales, Australia
}

(Manuscript received 12 August 2021, in final form 3 November 2021)

\begin{abstract}
Western boundary current (WBC) extensions such as the East Australian Current (EAC) southern extension are warming 2-3 times faster than the global average. However, there are nuances in the spatial and temporal variability of the warming that are not well resolved in climate models. In addition, the physical drivers of ocean heat content (OHC) extremes are not well understood. Here, using a high-resolution ocean model run for multiple decades, we show nonuniform warming trends in $\mathrm{OHC}$ in the $\mathrm{EAC}$, with strong positive trends in the southern extension region $\left(\sim 36^{\circ}-38^{\circ} \mathrm{S}\right)$ but negative $\mathrm{OHC}$ trends equatorward of $33^{\circ} \mathrm{S}$. The $\mathrm{OHC}$ variability in the EAC is associated with the formation of anticyclonic eddies, which is modulated by transport $\sim 880 \mathrm{~km}$ upstream (EAC mode) and the westward propagation of Rossby waves (eddy mode). Diagnosing the drivers of temperature extremes has implications for predictability both in the EAC and in WBCs more broadly, where ocean warming is already having considerable ecological impacts.
\end{abstract}

KEYWORDS: Australia; Eddies; Mesoscale models; Ocean circulation; Ocean dynamics; Rossby waves; Transport; Ocean models; Oceanic variability; Interannual variability

\section{Introduction}

Major subtropical ocean gyres, and particularly their western boundary currents (WBCs), are shifting poleward in response to global warming (Hu et al. 2015; Yang et al. 2016, 2020). In the Southern Hemisphere, the strengthening and poleward shift of westerly winds associated with a positive southern annular mode (SAM) (Cai et al. 2005; Cai 2006; Beal et al. 2011) is contributing to the spinup of the Southern Hemisphere super gyre (Qu et al. 2019). The East Australian Current (EAC) is one such WBC that has penetrated southward over the past 60 years (Ridgway 2007; Cai et al. 2005), and the EAC southern extension is projected to get stronger and warmer in the future (Oliver and Holbrook 2014; Bull et al. 2020). Surface ocean warming has increased in the EAC southern extension with warming rates of 2-3 times the global mean (Wu et al. 2012); however, temperature increases are nonuniform in shelf waters along the path of the EAC (Malan et al. 2021). In the Tasman Sea, warm ocean heat content (OHC) anomalies in the upper $2000 \mathrm{~m}(\mathrm{OHC} 2000)$ show a robust link with the occurrence, location, and intensity of marine heatwaves (MHWs) on interannual to decadal time scales (Behrens et al. 2019). Thus, investigating the ocean warming patterns, trends, and potential drivers of $\mathrm{OHC}$ in the EAC system is critical for understanding future temperature changes and predicting MHWs in the EAC southern extension and in WBCs more broadly.

\footnotetext{
๑Denotes content that is immediately available upon publication as open access.
}

Corresponding author: Junde Li, junde.li@unsw.edu.au
The EAC system is characterized by an energetic mesoscale eddy field (Everett et al. 2012). When the EAC separates from the coast, anticyclonic eddies shed from the main jet due to barotropic instabilities of the mean flow (Bowen et al. 2005). In addition, the EAC transport variability at $25^{\circ} \mathrm{S}$ is anticorrelated with transport in the EAC southern extension (Sloyan and O'Kane 2015). Eddy-rich regions are becoming more eddying (Martínez-Moreno et al. 2021), and eddy activity is projected to increase in the future (Matear et al. 2013), with a higher proportion of longer-lived and more stable anticyclonic (warm-core) eddies relative to cyclonic (cold-core) eddies (Oliver et al. 2015), which is projected to increase the frequency of ocean temperature extremes in the EAC southern extension (Oliver et al. 2015). Meanwhile, the poleward transport upstream of the EAC separation is projected to decrease in a future climate (Oliver and Holbrook 2014; Bull et al. 2020). In addition, the Agulhas Current (the WBC of the Indian Ocean), has been shown to be "broadening" rather than "strengthening" as a result of more eddy activity (Beal and Elipot 2016). However, the role of eddies in driving OHC anomalies is not clear. Hence there is a need to better understand the relationship between variability and trends in poleward transport (upstream) and the role of eddies in driving $\mathrm{OHC}$ anomalies in the EAC southern extension.

Among the mechanisms thought to influence the EAC separation, the westward propagation of Rossby waves (Godfrey et al. 1980) has also been considered an important factor. Variations in the EAC and EAC southern extension have been related to remote wind forcing in the South Pacific (Hill et al. 2010), where anticyclonic (cyclonic) wind stress curl fields generate downwelling (upwelling) and trigger downwelling (upwelling) Rossby waves. Hence historically it was thought that Rossby waves govern the formation of warm-core anticyclonic eddies (Nilsson and Cresswell 1980; Marchesiello and 
Middleton 2000) shed from the EAC jet. It is also thought that Rossby waves play a role in connecting westward-propagating sea level anomalies (SLA) to the EAC southern extension transport anomalies, which in turn influence the likelihood of advection-dominated MHWs (Li et al. 2020). Therefore, examining the role of Rossby waves in modulating the $\mathrm{OHC}$ variability in the EAC southern extension may be beneficial to improve the potential predictability of temperature extremes such as MHW events.

Here we investigate the physical drivers of $\mathrm{OHC}$ variability in the EAC system using a long-term (22-yr), high-resolution $(2.5-6 \mathrm{~km})$ ocean model to achieve three goals. First, we investigate the nonuniform warming trends and dominant warming patterns in the EAC. Second, we examine the mechanisms controlling $\mathrm{OHC}$ variability in the EAC southern extension and the role of anticyclonic eddy shedding. Third, we identify the linkage between Rossby waves and $\mathrm{OHC}$ variability, demonstrating the potential predictability of $\mathrm{OHC}$ in the EAC southern extension. These results may have an application to the other Southern Hemisphere WBCs, which are also warming at a rapid rate.

\section{Data and methods}

\section{a. Model description and simulations}

We use a configuration of the Regional Ocean Modeling System (ROMS) model for the EAC system as described in $\mathrm{Li}$ et al. (2021a,b) and previous studies (Kerry et al. 2016; Kerry and Roughan 2020) that has been well validated. ROMS is a free-surface, terrain-following, and primitive equation ocean model solved on a horizontal curvilinear grid with a splitexplicit time-stepping scheme (Shchepetkin and McWilliams 2005). The model domain extends from $25.3^{\circ}$ to $38.5^{\circ} \mathrm{S}$ along the southeastern Australian coast and nearly $1000 \mathrm{~km}$ offshore. The model grid is rotated $20^{\circ}$ clockwise to be oriented in the alongshore and cross-shore directions. The model has a variable horizontal resolution of $2.5-6 \mathrm{~km}\left(1 / 44^{\circ}-1 / 18^{\circ}\right)$ in the cross-shore direction and $5 \mathrm{~km}\left(1 / 22^{\circ}\right)$ in the alongshore direction, which is suitable for resolving the mesoscale eddies in the EAC system. In the vertical, the model has 30-s layers with a higher resolution in the upper 400-m depth and near the bottom boundary layer. The model bathymetry was obtained from the 50-m high-resolution Multibeam Dataset for Australia from Geoscience Australia (Whiteway 2009). We use the 2.5-level, second-moment turbulence closure scheme to parameterize the vertical turbulent mixing of momentum and tracers (Mellor and Yamada 1982). The Chapman conditions (Chapman 1985) are applied to the sea surface height (SSH), and Flather conditions (Flather 1976) are applied to the barotropic velocity. The lateral boundary conditions for baroclinic velocity, temperature, and salinity are specified as radiation conditions at the northern and eastern boundaries and clamped conditions at the southern boundaries. The western boundary is land. The model initial and boundary conditions are taken from CSIRO's Australia Bluelink Reanalysis (BRAN2016) with a horizontal resolution of $1 / 10^{\circ}$ and 51 vertical layers (Oke et al. 2008, 2013).
The 22-yr simulation is forced from the hourly 12-km Bureau of Meteorology Atmospheric high-resolution Regional Reanalysis for Australia (BARRA-R) (Su et al. 2019) and includes the barotropic tidal constituents extracted from the TPXO8 global tidal model (Egbert and Erofeeva 2002). Previous studies using the model output (Kerry and Roughan 2020; Malan et al. 2021; Li et al. 2021b) provide us with the confidence to use this model to investigate the drivers of $\mathrm{OHC}$ in the EAC.

\section{b. EAC eastern and southern extension definitions}

We use the terms EAC eastern extension and EAC southern extension, which were introduced in Oke et al. (2019), to define the eastward and southward flow stemming from the EAC jet and its eddies downstream of the EAC separation point. The eastward flow toward northern New Zealand is referred to as the EAC eastern extension, which has previously been referred to as the Tasman Front. The southward flow toward Tasmania is referred to as the EAC southern extension, which has previously been referred to simply as the EAC extension.

\section{c. Calculations of OHC2000 and SLA}

$\mathrm{OHC}$ is a measure of the heat accumulation received by Earth to quantify the rate of global warming (von Schuckmann et al. 2016; Cheng et al. 2020). Ocean warming rates for the upper 2000-m-depth layer reached record rates of $0.9 \pm$ $0.1 \mathrm{~W} \mathrm{~m}^{-2}$ for the global ocean area over the period 1993-2018 (von Schuckmann et al. 2020), hence here we integrate OHC over the top $2000 \mathrm{~m}$ of the water column. OHC2000 is defined as

$$
\mathrm{OHC} 2000=\int_{-2000}^{0} \rho c_{p} T(z) d z,
$$

where $\rho, c_{p}$, and $T(z)$ are the density, specific heat capacity and temperature of seawater, respectively. We define OHC2000 larger (smaller) than the mean OHC2000 plus (minus) one standard deviation over the 22-yr period as representing the ocean temperature extremes in the upper $2000 \mathrm{~m}$ of the ocean. SLA is calculated by removing the 22-yr mean SSH at each model grid cell from the daily SSH output.

\section{d. Trends, significance, and uncertainties}

All the linear trends are estimated by applying a linear least squares regression model to the spatially integrated time series. For the trend maps, the linear trends are computed for each grid point and statistically tested using a modified Mann-Kendall test (Yue and Wang 2004). The autocorrelations within the time series have also been taken into account in this statistical test, and trends with a $p$ value lower than 0.05 are considered significant. The uncertainties of trends correspond to the standard error, which is the standard deviation of the time series divided by the square root of the effective sample size from the Mann-Kendall test. 


\section{e. Energy conversion terms}

The surface velocity components $(u, v)$ can be decomposed into their time-mean $(\bar{u}, \bar{v})$ and time-varying $\left(u^{\prime}, v^{\prime}\right)$ velocities, where overbars denote time averages over the whole simulation period. Therefore, the eddy kinetic energy (EKE) is defined as

$$
\mathrm{EKE}=\frac{1}{2}\left(u^{\prime 2}+\boldsymbol{v}^{\prime 2}\right)
$$

Based on the energetics analysis (Kang and Curchitser 2015), the energy conversion term KmKe through barotropic instability is defined as follows:

$$
\mathrm{KmKe}=-\rho_{0}\left[\overline{u^{\prime} u^{\prime}} \frac{\partial \bar{u}}{\partial x}+\overline{u^{\prime} v^{\prime}} \frac{\partial \bar{u}}{\partial y}+\overline{v^{\prime} u^{\prime}} \frac{\partial \bar{v}}{\partial x}+\overline{v^{\prime} v^{\prime}} \frac{\partial \bar{v}}{\partial y}\right],
$$

where $\rho_{0}$ is the density of seawater assumed to be a constant $1025 \mathrm{~kg} \mathrm{~m}^{-3}$. The $\mathrm{KmKe}$ represents the energy transfer rate from mean kinetic energy to EKE, with positive values indicating the eddy formation due to barotropic instabilities of the mean flow (Kang and Curchitser 2015). The KmKe used here is averaged over the upper $450 \mathrm{~m}$, where the EKE is highest (Kerry et al. 2018; Kerry and Roughan 2020; Li et al. 2021b).

\section{f. Significance test}

We use a Monte Carlo method used in Ryan et al. (2021) and $\mathrm{Li}$ et al. (2021b) to test the significance of the composite analysis fields, including the OHC2000, SLA, EKE, and $\mathrm{KmKe}$. There are eight high-OHC periods with a total of 1553 days and seven low-OHC periods with 1696 days used for the respective composite analyses. For the simulation of the eight high-OHC events, we randomly select eight days from the whole 22-yr period and create eight events of the same duration as the eight high-OHC events, so as to represent eight individual randomly generated events. For each random event, we create a composite by averaging the selected consecutive days in the simulated eight high-OHC events to get composite fields during (random) high-OHC periods. We repeated this procedure $10^{5}$ times and produced a distribution of the composite fields at each spatial grid in our model. The 5th and 95th percentiles of the distribution are chosen as the significance levels. Similarly, the same Monte Carlo simulation method is performed to test the significance of the composites during the low-OHC periods.

Lagged cross-correlations are calculated between the daily 1-yr low-pass filtered time series of SLA and OHC2000 with the linear trend removed. To take into account the autocorrelation in our data, we use the effective number of degrees of freedom $N_{\text {eff }}$ defined as (Li et al. 2013)

$$
\frac{1}{N_{\mathrm{eff}}} \approx \frac{1}{N}+\frac{2}{N} \sum_{j=1}^{N} \frac{N-j}{N} \rho_{X X}(j) \rho_{Y Y}(j),
$$

where $N$ is the number of observations, and $\rho_{X X}(j)$ and $\rho_{Y Y}(j)$ are the autocorrelation coefficients of two time series, $X$ and $Y$, at time lag $j$, respectively. Then, we evaluate the statistical significance of linear correlation coefficients by calculating $p$ values from the $t$ statistic:

$$
T=r \sqrt{\frac{N_{\mathrm{eff}}-2}{1-r^{2}}}
$$

where $r$ is the cross-correlation coefficient. Only lagged crosscorrelation coefficients statistically significant above the $95 \%$ confidence level are shown in the following correlation plots.

\section{Results}

a. Nonuniform trends in ocean warming and eddy activity in the EAC system

The southward shift of the Southern Hemisphere super gyre has resulted in an intensification of the EAC southern extension, but a weakening of the EAC equatorward of $30^{\circ} \mathrm{S}$ (Cai 2006). We show positive OHC2000 trends in the EAC southern extension and negative OHC2000 trends north of $33^{\circ} \mathrm{S}$ (Fig. 1a). These nonuniform trends of OHC2000 are consistent with the linear trend of estimated OHC2000 based on reconstructed temperature fields from 1993 to 2015 (Cheng et al. 2017). The time series of OHC2000 averaged over the region where the OHC2000 warming, positive SLA, and EKE trend are the strongest (hereafter referred to as the Tasman OHC box; the black box in Figs. 1a-c) shows that the warming trend in the Tasman OHC box is $(0.60 \pm 0.22) \times$ $10^{10} \mathrm{~J} \mathrm{~m}^{-2}$ decade $^{-1}$ from 1994 to 2016 (statistically significant above the $95 \%$ confidence level; Fig. 1d).

As the ocean thermal expansion associated with increased $\mathrm{OHC}$ is a major contributor to sea level rise (Cazenave et al. 2018), we show that the spatial distribution of the SLA trend is similar to that of the $\mathrm{OHC} 2000$ trend, with nonuniform patterns (Fig. 1b). The OHC2000 cooling trends north of $33^{\circ} \mathrm{S}$ lead to a sea level depression from $\sim 30^{\circ}$ to $33^{\circ} \mathrm{S}$. On the other hand, consistent with previous observations (Malan et al. 2021), the SLA trends are significantly positive in most regions south of $33^{\circ} \mathrm{S}$, with the highest increasing sea level trend in the Tasman OHC box $\left(0.13 \pm 0.04 \mathrm{~m} \mathrm{decade}^{-1}\right.$, statistically significant above the $95 \%$ confidence level; Fig. 1e). In the Tasman OHC box, the positive OHC2000 and SLA trends are associated with increased mesoscale eddy activity (Fig. 1c), with an increasing EKE trend of $0.03 \pm 0.02 \mathrm{~m}^{2} \mathrm{~s}^{-2}$ decade $^{-1}$ (statistically significant above the $95 \%$ confidence level; Fig. 1f). Conversely, the region to the north of the Tasman OHC box exhibits negative EKE trends, indicating a reduction of mesoscale eddy activity in the EAC eastern extension consistent with recently demonstrated nonuniform EKE trends in the EAC southern and eastern extension (Martínez-Moreno et al. 2021).

\section{b. Spatial patterns of $O H C$ and SLA variability}

The OHC2000, SLA, and EKE show strong peaks at the annual and interannual time scale within the Tasman $\mathrm{OHC}$ box (spectral analysis; Fig. 2). To detect the most correlated patterns between OHC2000 and SLA, we conducted a singular value decomposition (SVD) analysis of the 1-yr low-pass filtered OHC2000 anomalies and SLA. The two leading SVD 

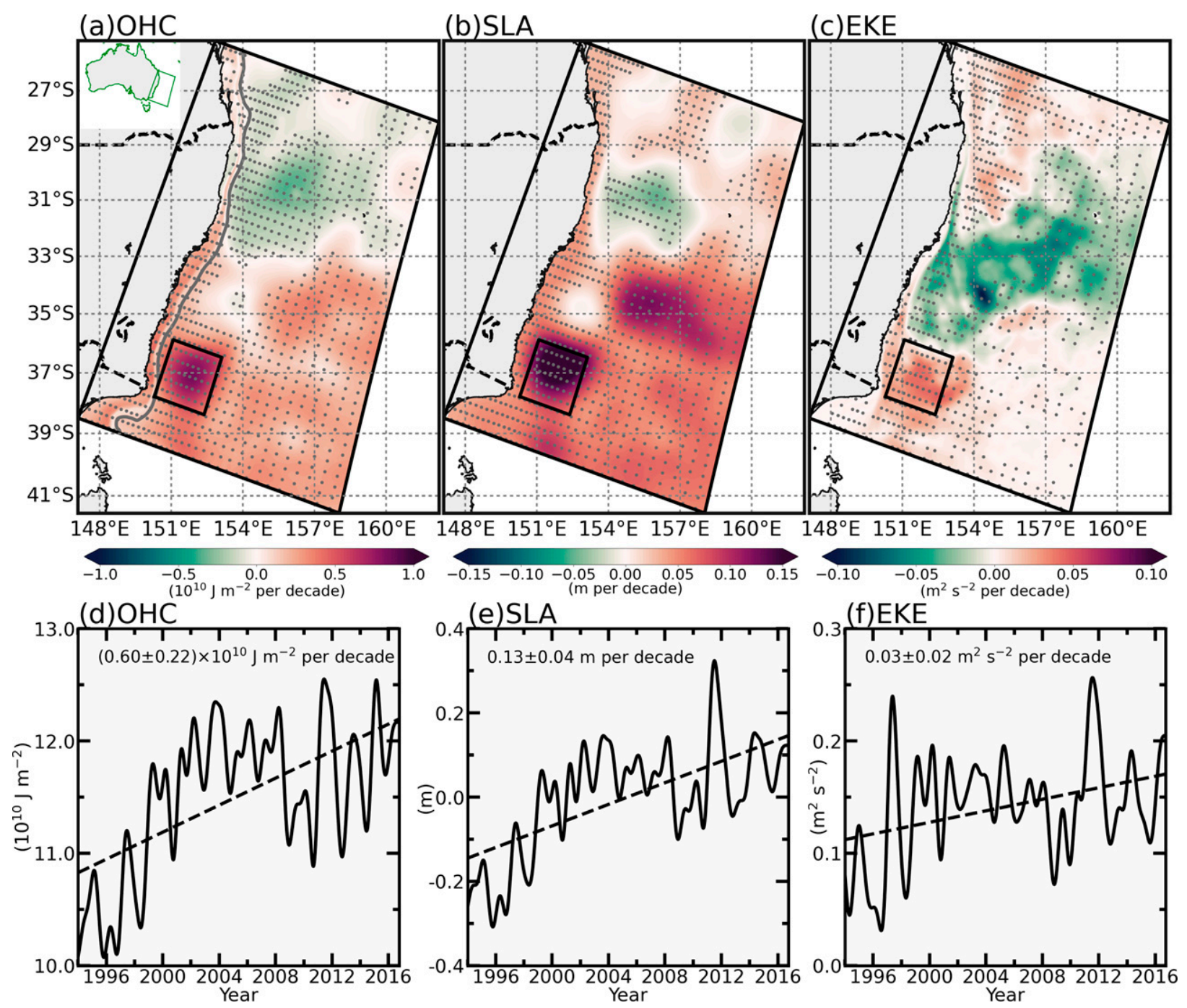

FIG. 1. (a) Spatial distribution of OHC2000 trends between 1994 and 2016. The gray stippling indicates regions that are statistically significant above the $95 \%$ confidence level. The black box indicates the Tasman OHC box $\left(\sim 35.9^{\circ}-38.4^{\circ} \mathrm{S}, \sim 150.3^{\circ}-153.1^{\circ} \mathrm{E}\right)$. The gray line indicates the 2000-m isobath. (b),(c) As in (a), but for the SLA and EKE. (d) Time series of the 1-yr low-pass filtered OHC2000 averaged over the Tasman OHC box (solid black line) with errors estimated above $95 \%$ confidence level. The dashed line indicates the linear trend. (e),(f) As in (d), but for the SLA and EKE.

modes of the coupled OHC2000 and SLA variation account for $60.3 \%$ of the total covariance and have consistent spatial patterns (Figs. 3a-d). The first SVD mode of OHC2000 and SLA, explaining $35.9 \%$ of the total covariance, exhibits positive anomalies south of $32^{\circ} \mathrm{S}$ and negative anomalies along the EAC path north of $32^{\circ} \mathrm{S}$ (Figs. 3a,c). This oppositely signed pattern of anomalies north and south of $32^{\circ} \mathrm{S}$ suggests that the first SVD mode is associated with the EAC variability, hereafter referred to as the EAC mode. The second SVD mode accounts for $24.4 \%$ of the total covariance and shows eddylike structures with alternating positive and negative anomalies south of $32^{\circ} \mathrm{S}$ (Figs. 3b,d), hereafter referred to as the eddy mode. It is worth noting that the Tasman OHC box has the largest positive anomalies in both the EAC mode and the eddy mode (Figs. 3a-d), implying that both modes contribute to the OHC2000 variability in the Tasman box. Moreover, the principal component time series of the two leading modes for OHC2000 are significantly correlated (Fig. 3e) with those for SLA, with correlations of 0.92 and 0.94 for the first and second modes (statistically significant above the $95 \%$ confidence level), respectively. These robust correlations not only validate that ocean thermal expansion dominates the sea level rise in the EAC but also suggest that the $\mathrm{OHC} 2000$ variability is highly correlated with the SLA variability in the EAC.

To extract the most prominent patterns of interannual variability, we applied a multivariate empirical orthogonal function (EOF) to the 1-yr low-pass filtered OHC2000 anomalies and SLA. The first and second EOF modes explain $20.1 \%$ and $12.3 \%$ of the total variance, respectively. Interestingly, the spatial patterns of the two leading EOF modes are 

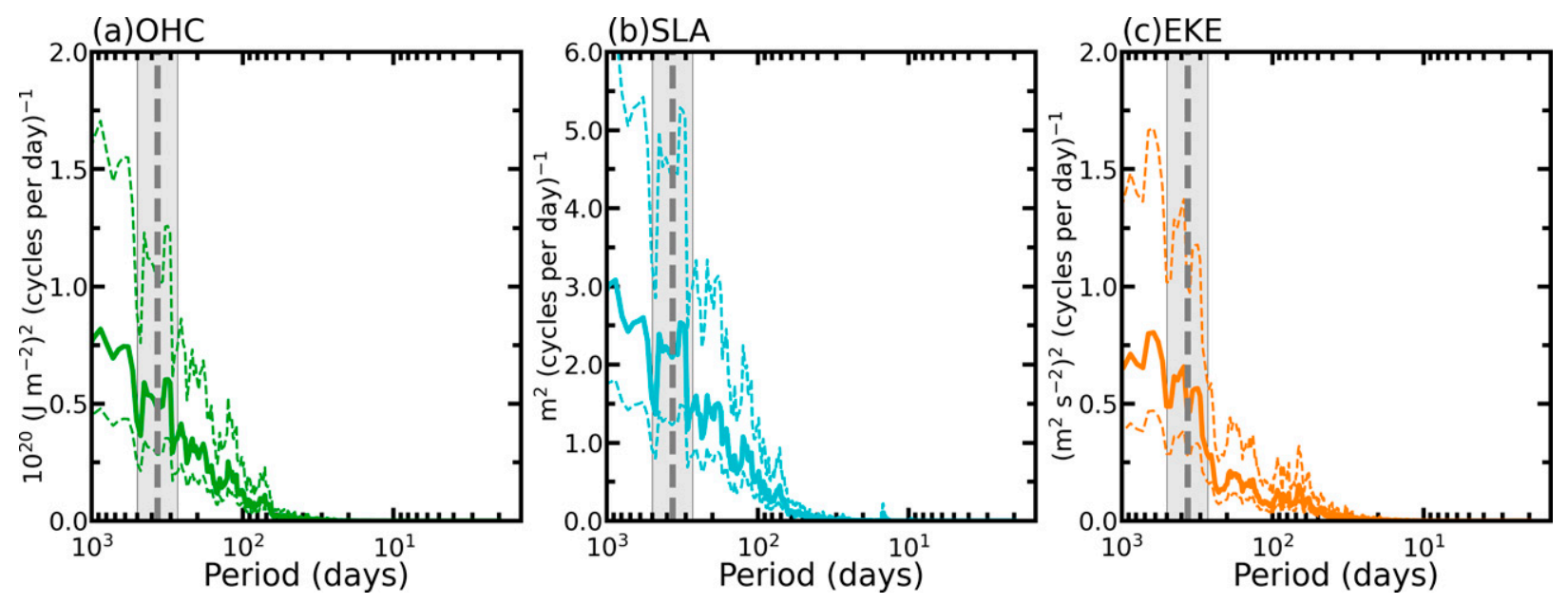

FIG. 2. (a) Frequency spectra of OHC2000 averaged in the Tasman OHC box over the 22 years. The solid green line indicates the frequency spectra from unfiltered OHC2000 time series. The green dashed lines represent the $95 \%$ confidence intervals. The dashed gray line indicates the frequency corresponding to the annual period, and the gray shaded area shows the frequency band corresponding to periods of 270-500 days. (b),(c) As in (a), but for the SLA (blue line) and surface EKE (orange line).

consistent with that of the two leading SVD modes (Figs. 4a-d), implying that the highly correlated EAC mode and eddy mode also dominate the OHC2000 and SLA variability in the EAC. Furthermore, the principal component time series of the two leading EOF modes show statistically significant relationships with the 1-yr low-pass filtered OHC2000 time series averaged within the Tasman OHC box (hereafter referred to as the OHC2000 index), with a correlation of 0.63 for the first mode and 0.52 for the second mode (statistically significant above the 95\% confidence level), respectively (Fig. 4e). Therefore, interannual variability in $\mathrm{OHC} 2000$ in the Tasman OHC box correlates to the variability of the two leading EOF modes with similar patterns shown in the EAC mode and eddy mode.

\section{c. Linkage between transport upstream and $\mathrm{OHC}$ variability}

We have shown that the positive trends of OHC2000, SLA, and EKE are largest in the Tasman OHC box, and that OHC2000 and SLA have the highest variability in that region. The 1-yr low-pass filtered SLA and EKE time series averaged within the Tasman OHC box show statistically significant relationships with the $\mathrm{OHC} 2000$ index, with a correlation of 0.88 for SLA and 0.64 for EKE (statistically significant above the $95 \%$ confidence level), respectively (Fig. 5a). This suggests a robust link between eddy-associated SLA variability and OHC2000 variability in the Tasman OHC box. Here we define high-OHC (low-OHC) periods when the OHC2000 index is larger (smaller) than the mean OHC2000 plus (minus) one standard deviation of the OHC2000 time series (Fig. 5a) (Li et al. 2021b). Periods with a high-OHC anomaly correspond with periods of high eddy activity and elevated SLA in the Tasman OHC box, and the inverse is true for a low-OHC anomaly.

To investigate the mechanisms responsible for the OHC2000 variability in the Tasman $\mathrm{OHC}$ box, we conducted a composite analysis of OHC2000 anomalies, SLA, EKE, and the energy conversion term from mean kinetic energy to EKE ( $\mathrm{KmKe})$ for the high-OHC and low-OHC periods (Fig. 5). Positive $\mathrm{KmKe}$ indicates that eddies drain energy from the mean flow through barotropic instabilities to drive an eddy shedding event (Kang and Curchitser 2015). It is evident that the large positive OHC2000 anomalies in the Tasman OHC box during the high-OHC periods are associated with increased eddy activity in the EAC southern extension (Figs. 5b,c). Barotropic instability extends the length of the EAC and into the Tasman OHC box. High positive $\mathrm{KmKe}$ (Fig. 5e) in the Tasman OHC box increases the energy transfer from mean flow to eddies, resulting in elevated EKE (Fig. 5d), accompanied by large positive OHC anomalies and SLA (Figs. 5b,c). This implies an increase in anticyclonic (warmcore) eddies in the EAC southern extension (Tasman OHC box). During the low-OHC periods in the EAC southern extension, we see that $\mathrm{KmKe}$ and EKE are a maximum upstream of the Tasman OHC box (Figs. 5h,i). As the eddy activity occurs farther north, OHC2000 anomalies and SLA are a minimum in the Tasman OHC box (Figs. 5f,g) with positive anomalies north (upstream) of the box. In this scenario, the EAC does not extend southward into the Tasman OHC box.

Composites of SSH and eastward and northward velocities during the high-OHC and low-OHC periods tell a consistent story. A prominent anticyclonic structure (Fig. 6a) can be seen in the Tasman OHC box during the high-OHC periods showing that the EAC separates from the coast at the southern end of its range. Composite velocities show that the EAC jet penetrates farther south (Figs. $6 \mathrm{c}$ and $7 \mathrm{c}$ ) and turns eastward (Figs. 6b and 7a) to form the EAC return flow. We calculate the EAC separation latitude, which shows that during the high-OHC periods the EAC separates within the Tasman OHC box more often ( $8.7 \%$; Fig. $6 \mathrm{~d})$. In contrast, during the low-OHC period, the EAC jet separation retracts to the north (Figs. $6 \mathrm{f}-\mathrm{h}$ and $7 \mathrm{~b}, \mathrm{~d}$ ) with a significantly decreased separation in the Tasman $\mathrm{OHC}$ box $(0.3 \%$; Fig. $6 \mathrm{i})$. 
(a)SVD1(OHC) (b)SVD2(OHC)

(c)SVD1(SLA)

(d)SVD2(SLA)
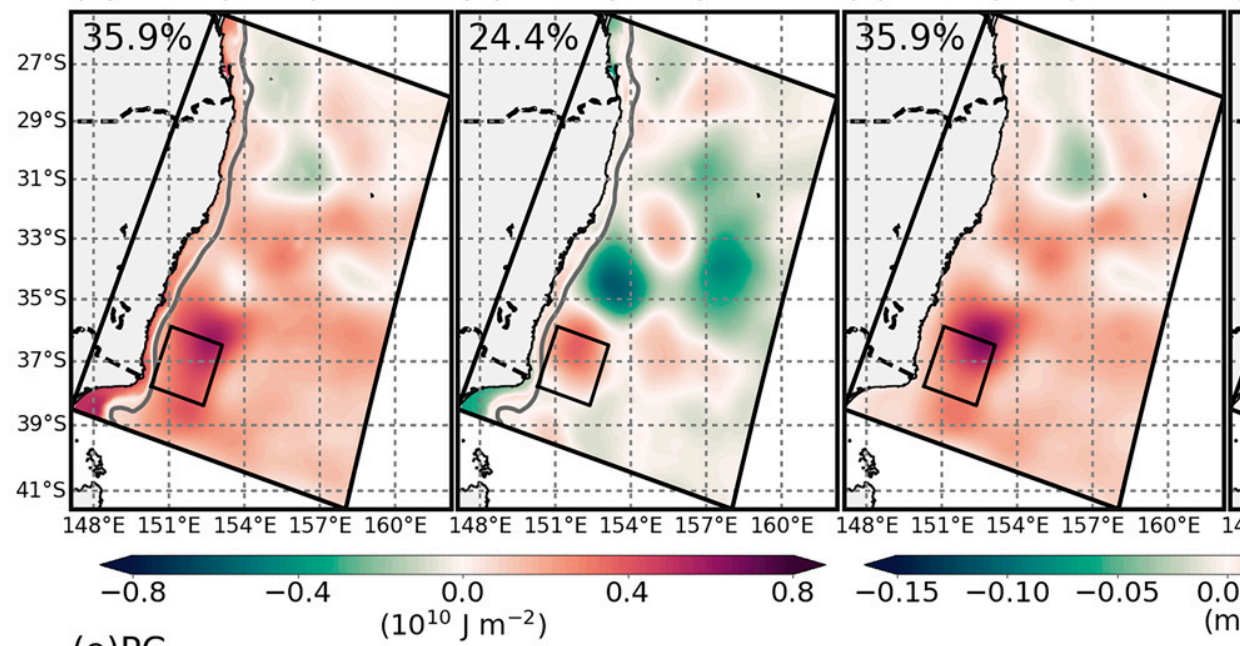

\section{(d)SVD2(SLA)}

(e)PC

$\left(10^{10} \mathrm{~J} \mathrm{~m}^{-2}\right)$
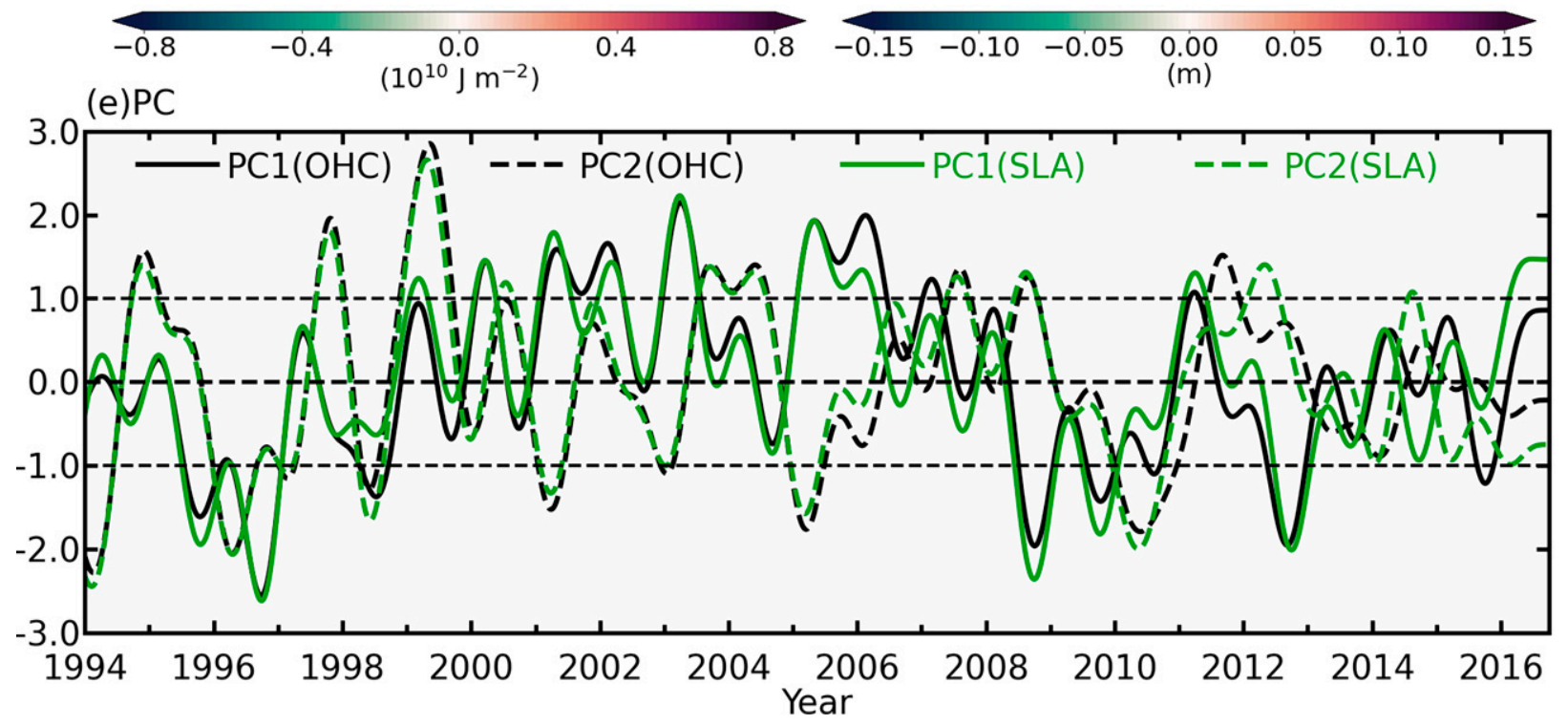

FIG. 3. Spatial patterns of the (a) first and (b) second SVD modes for the 1-yr low-pass filtered OHC2000 from 1994 to 2016. (c),(d) As in (a) and (b), but for the SLA. (e) Time series of the first (solid line) and second (dashed line) SVD principal components for OHC2000 (black line) and SLA (green line).

Following the approach in Kerry and Roughan (2020) and Li et al. (2021b), we compute the poleward transport over the cross-sectional area inside the $-0.05 \mathrm{~m} \mathrm{~s}^{-1}$ contour in the alongshore velocity mean. To examine the physical drivers of eddy activity in the Tasman Sea, we calculate the zero-lag correlations between the 1-yr low-pass filtered time series of poleward transport every $5 \mathrm{~km}$ and the OHC2000 index. The significantly negative correlation equatorward of $35^{\circ} \mathrm{S}$ indicates the transport is anticorrelated with the OHC2000 index (Fig. 6e), particularly north of $28^{\circ} \mathrm{S}$ with a mean correlation of -0.51 (statistically significant above the $95 \%$ confidence level). A clear positive correlation between the transport and the $\mathrm{OHC} 2000$ index can be seen south of $35^{\circ} \mathrm{S}$, particularly within the latitudes of the Tasman $\mathrm{OHC}$ box with a mean correlation of 0.75 (statistically significant above the $95 \%$ confidence level). The composite northward velocities (Figs. 6c,h) and velocity anomalies (Figs. 7c,d) also reveal the negative and positive correlations north and south of $35^{\circ} \mathrm{S}$, respectively. Thus, a stronger EAC jet upstream corresponds to a weaker EAC in the Tasman OHC box, while a weak upstream EAC jet corresponds to increased penetration of the EAC into the Tasman OHC box.

Significantly trends in poleward transport along the EAC path are nonuniform and indicate that the EAC jet is weakening equatorward of $33^{\circ} \mathrm{S}$ and strengthening poleward of $35^{\circ} \mathrm{S}$, particularly around the latitudes of the Tasman $\mathrm{OHC}$ box $\left(\sim 36^{\circ} \mathrm{S}\right.$, where the positive trend is largest with a mean trend of $6.1 \mathrm{~Sv}$ decade ${ }^{-1}$, where $1 \mathrm{~Sv} \equiv 10^{6} \mathrm{~m}^{3} \mathrm{~s}^{-1}$; Fig. $6 \mathrm{j}$ ). The intensification of the EAC transport poleward of $35^{\circ} \mathrm{S}$ results from the southward shift of the subtropical gyre (Ridgway 2007; Yang et al. 2016, 2020). This pattern of decreasing (increasing) transport upstream (downstream) of $35^{\circ} \mathrm{S}$ is consistent with the nonuniform trends of OHC, SLA, and EKE we observed, implying that a decrease in EAC transport 
(a)EOF1(OHC) (b)EOF2(OHC) (c)EOF1(SLA) (d)EOF2(SLA)
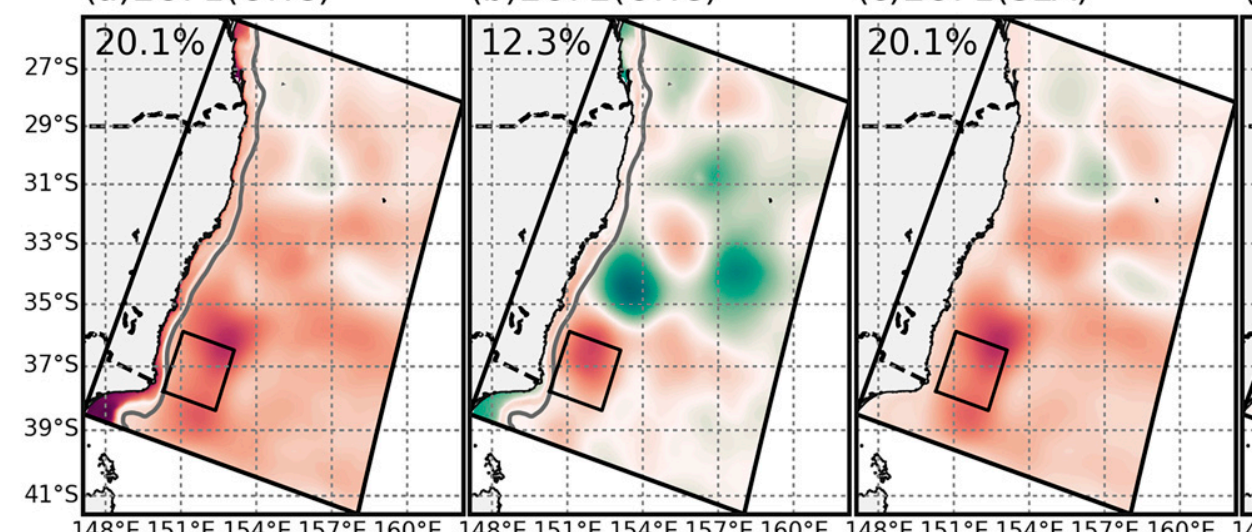

$148^{\circ} \mathrm{E} 151^{\circ} \mathrm{E} 154^{\circ} \mathrm{E} 157^{\circ} \mathrm{E} 160^{\circ} \mathrm{E}$

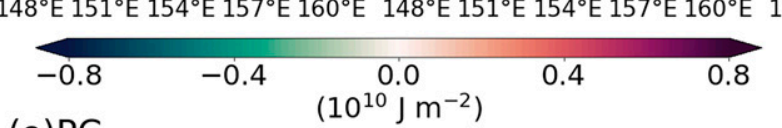

(e) $\mathrm{PC}$

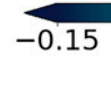

(d)EOF2(SLA)

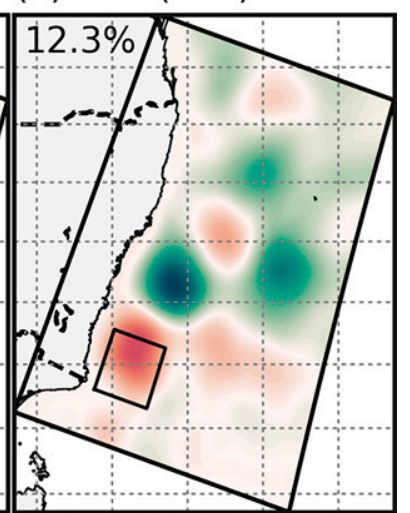

$148^{\circ} \mathrm{E} 151^{\circ} \mathrm{E} 154^{\circ} \mathrm{E} 157^{\circ} \mathrm{E} 160^{\circ} \mathrm{E}$

(m)

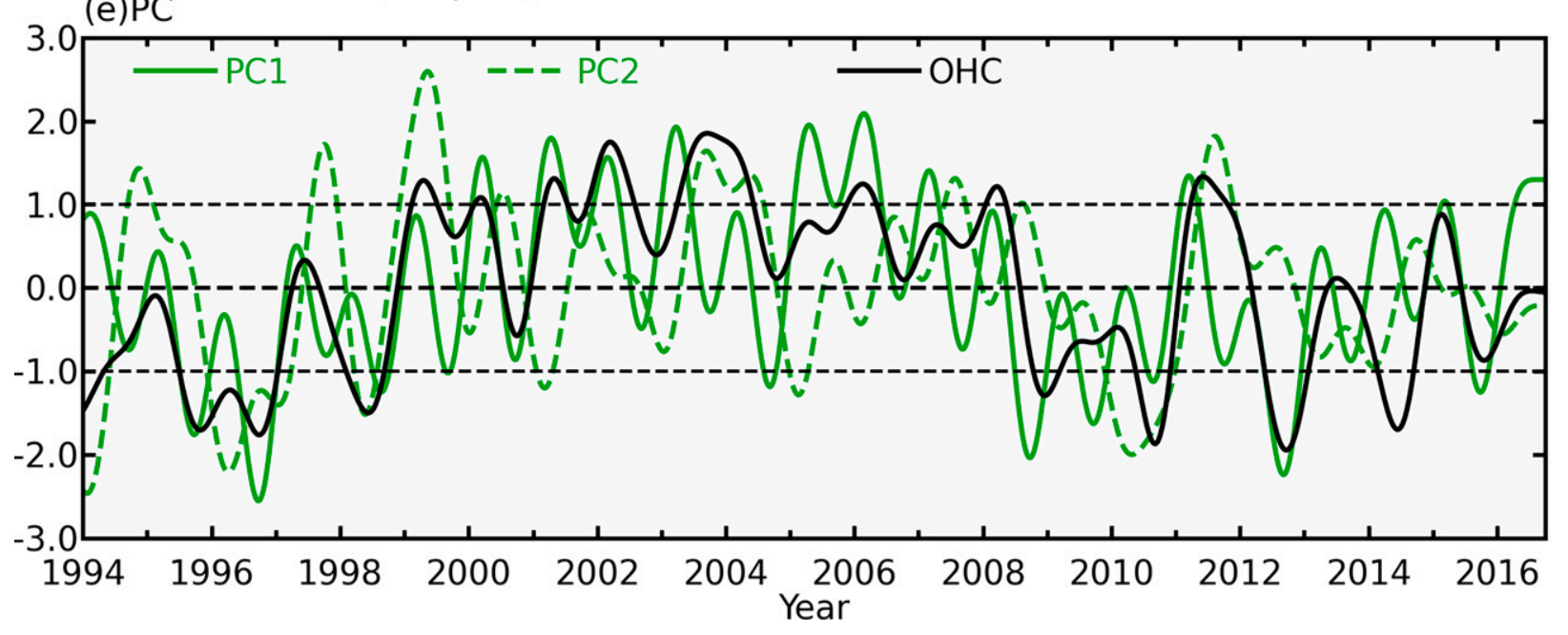

FIG. 4. Spatial patterns of the (a) first and (b) second EOF modes for the 1-yr low-pass filtered OHC2000 from 1994 to 2016. (c),(d) As in (a) and (b), but for the SLA. (e) Time series of the first (solid line) and second (dashed line) EOF principal components for OHC2000 (black line) and SLA (green line).

upstream leads to an increase in $\mathrm{OHC}$ in the Tasman $\mathrm{OHC}$ box in a warming climate.

Our composite analysis demonstrates that EAC transport (measured upstream) is a driver of OHC2000 variability in the Tasman OHC box. A weaker EAC (Fig. 7c) is relatively stable (Fig. 5e) and penetrates farther south (Figs. 6a-c), increasing the EAC transport (Fig. 7c) and the likelihood of EAC separation (Fig. 6d) in the Tasman OHC box. Anticyclonic eddies shed from the EAC jet when it separates from the coast (Fig. 6a), increasing EKE, SLA, and OHC2000 anomalies in the Tasman $\mathrm{OHC}$ box (Figs. 5b-d). A stronger upstream EAC (Fig. 7d) is more barotropically unstable (Fig. 5i), resulting in an equatorward retraction of the EAC separation (Figs. 6f-h) and therefore minima in EKE, SLA, and OHC2000 anomalies in the Tasman OHC box (Figs. 5f-h). Previous studies have suggested that the EAC southern extension is projected to intensify under global warming associated with weaker transport upstream (Oliver and Holbrook 2014; Bull et al. 2020). In light of our results, we suggest that the decrease in transport upstream will also lead to an increase in OHC2000 in the Tasman Sea in a future climate.

\section{d. The link between Rossby waves and OHC}

Rossby waves play a critical role in sea level variability (Sasaki et al. 2008), trends (Qiu and Chen 2006), and poleward transport in the EAC southern extension (Hill et al. 2010; Holbrook et al. 2011; Li et al. 2020). To understand the link between Rossby waves and OHC in the Tasman OHC box, we track the propagation of SLA and Rossby waves based on snapshots of the spatial distribution of lagged correlations between SLA and OHC2000 index (Fig. 8). At a lag of -800 days (Fig. 8 b), significantly positive correlations propagate into the model domain at $\sim 32^{\circ}-34^{\circ} \mathrm{S}$ where long Rossby waves emanate (Sasaki et al. 2008) from around northern New Zealand. This is consistent with Li et al. (2020), who demonstrated that the SLA around New Zealand (as an 

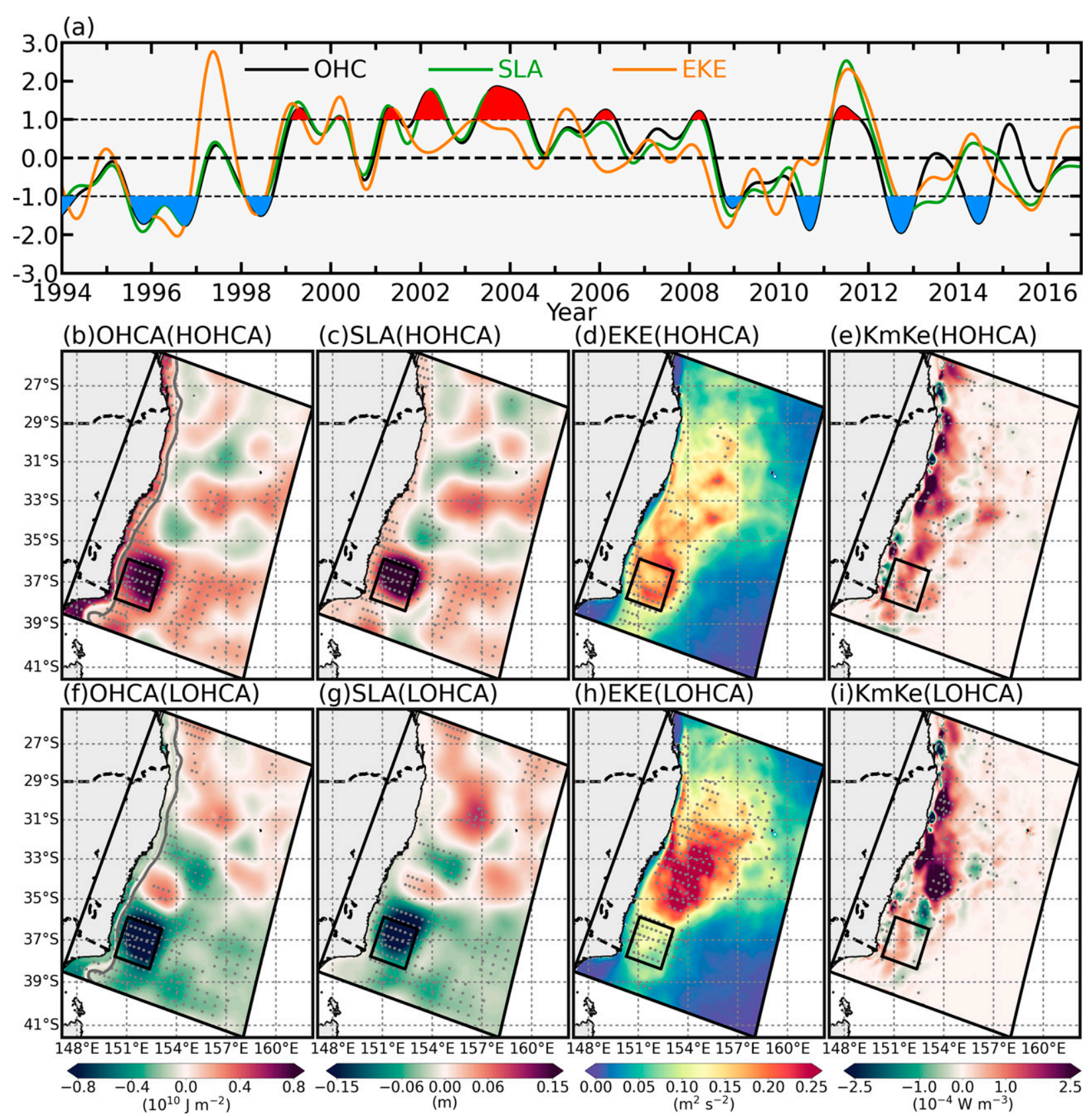

FIG. 5. (a) Time series of the 1-yr low-pass filtered OHC2000 (black line), SLA (green line), and surface EKE (orange line) averaged over the Tasman OHC box. The time series are normalized by their respective standard deviation (STD) with the linear trends removed. Periods when OHC2000 is larger (smaller) than 1.0 STD are highlighted in red (blue). Composites of (b) OHC2000 anomalies, (c) SLA, (d) surface EKE, and (e) KmKe averaged over the upper $450 \mathrm{~m}$ during the high-OHC periods. The gray stippling indicates significance above the $95 \%$ confidence level. (f)-(i) As in as (b)-(e), but for the low-OHC periods.

index) leads advective marine heatwaves (MHWs) in the western Tasman Sea by 2-3 years. A distinctive westward propagation can be found at a lag of -800 to -400 days (Figs. $8 \mathrm{~b}-\mathrm{e}$ ). Like other WBCs (Lu and Liu 2013), the EAC return flow acts as a dynamic barrier and blocks the Rossby waves from propagating farther westward, with no significant correlations in the eddy-dominated region west of $157^{\circ} \mathrm{E}$. Instead, when the Rossby waves reach around $157^{\circ} \mathrm{E}$, the significant positive correlations turn to propagate southwestward along a band between the mean SSH contour of 0.3 and $0.35 \mathrm{~m}$ (SSH band) (Figs. 8f-j). We find the highest positive correlations in the Tasman OHC box at a lag of -100 and 0 days (Figs. 8i,j).

To show the propagation of Rossby waves, we averaged the 1-yr low-pass filtered SLA and lagged correlation coefficient 

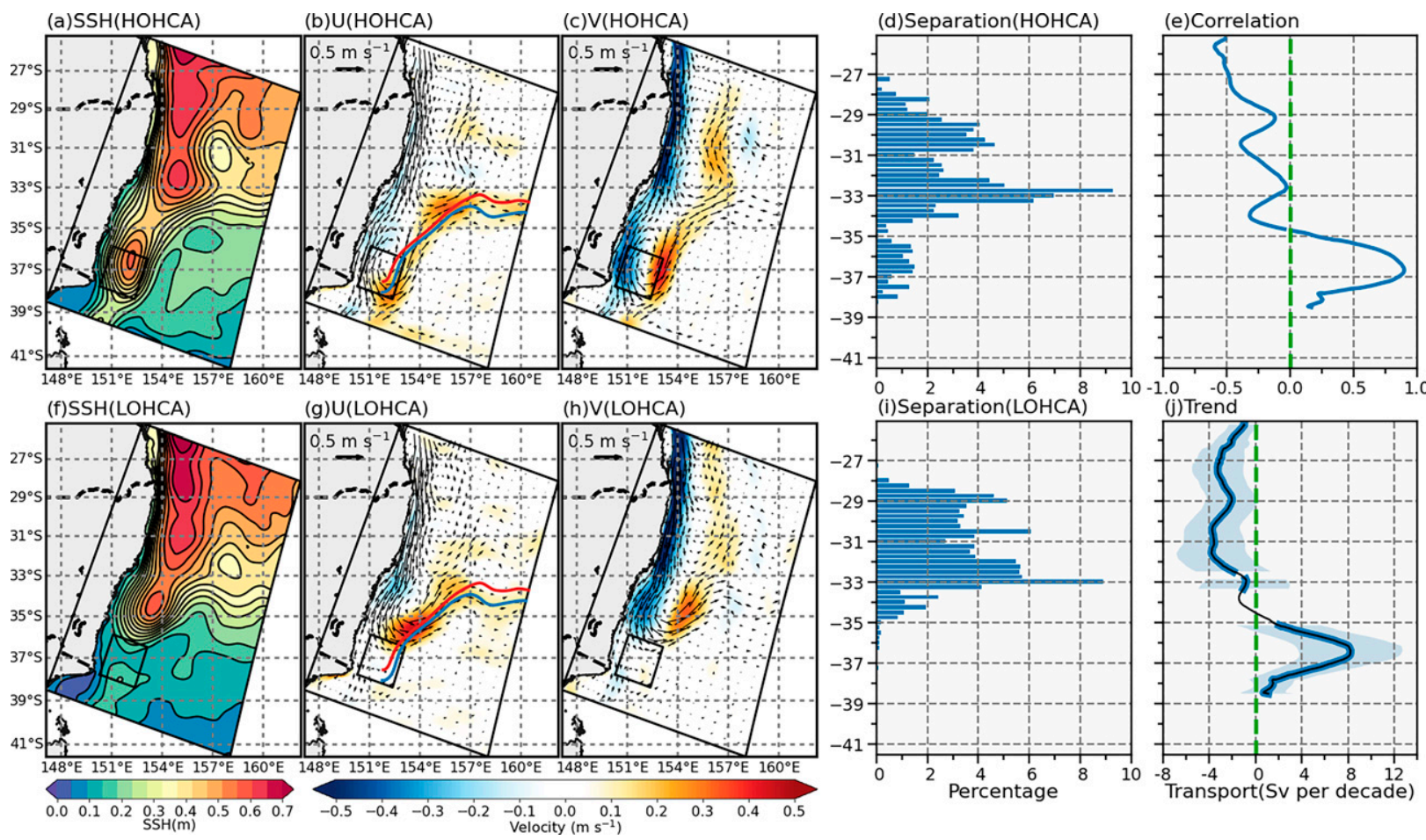

FIG. 6. Composites of (a) SSH, (b) surface eastward and (c) northward velocity component during the high-OHC periods. Blue line (red line) in (b) indicates the mean SSH contour of $0.3 \mathrm{~m}(0.35 \mathrm{~m})$. (d) Percentage occurrence of the composite EAC separation latitude during the high-OHC periods. (e) Correlation coefficients between the 1-yr low-pass filtered poleward volume transport and the OHC2000 index. (f)-(i) As in (a)-(d), but for the low-OHC periods. (j) Trends of poleward volume transport (thin black line). Thick blue line and blue shading indicate the trends and standard errors that are statistically significant above the $95 \%$ confidence level.

within the SSH band. Bands of positive and negative SLA are clearly observed (Fig. 9b), illustrating the westward propagating Rossby wave troughs and crests. This westward propagation of SLA also suggests that the SLA variability at $\sim 32^{\circ}-34^{\circ} \mathrm{S}\left(158^{\circ}-160^{\circ} \mathrm{E}\right)$ modulates the SLA variability in the Tasman OHC box, with a lead time of $\sim 600-800$ days (Fig. 9 c). It is noteworthy that most periods of positive SLA that are associated with high OHC2000 in the Tasman OHC box correspond to periods of weak poleward transport at $28^{\circ} \mathrm{S}$ (Figs. 9a,b), but only a few periods of negative SLA are associated with strong poleward transport upstream. This suggests an asymmetric response to Rossby waves for the SLA and $\mathrm{OHC} 2000$ in the Tasman OHC box when the upstream transport is strong or weak. When upstream transport is weak, EAC separation can be modulated by westward propagating Rossby waves, whereas when upstream transport is strong the separation is dominated by the existence of large barotropic instability north of the Tasman OHC box. Therefore, both upstream transport and Rossby waves are of critical importance for modulating the $\mathrm{OHC} 2000$ variability in the Tasman OHC box.

The westward propagation of Rossby waves plays an important role in the EAC separation (Godfrey et al. 1980) and anticyclonic eddy formation (Nilsson and Cresswell 1980; Marchesiello and Middleton 2000). As demonstrated in previous studies (Holbrook et al. 2011), downwelling Rossby waves triggered by downwelling wind stress curl anomalies in the interior of the South Pacific Ocean propagate into the Tasman Sea and lead to deeper pycnocline anomalies and positive SLA. When poleward transport at $28^{\circ} \mathrm{S}$ is weak associated with low SLA (Fig. 5c), the EAC jet is stable and penetrates farther south (Fig. 10a). In this case, the positive SLA at $\sim 32^{\circ}-34^{\circ} \mathrm{S}$ resulting from downwelling Rossby waves propagate southwestward along the SSH band, resulting in an anticyclonic eddy being pinched off and an increase in both OHC2000 and SLA in the Tasman OHC box. In contrast, a stronger transport at $\sim 28^{\circ} \mathrm{S}$ with high SLA (Fig. $5 \mathrm{~g}$ ) causes the EAC jet to be barotropically unstable (Fig. 10b). The separation latitude of the unstable EAC jet retracts to the north of the Tasman OHC box, leading to a decrease in OHC2000 in the Tasman OHC box. When upwelling Rossby waves propagate westward into the EAC system, negative SLA propagates southwestward along the SSH band and contributes to lower OHC2000 in the Tasman OHC box.

\section{Discussion and conclusions}

The EAC southern extension is warming 2-3 times the global average due to the spinup of the South Pacific subtropical gyre (Wu et al. 2012). However, the warming rates are 


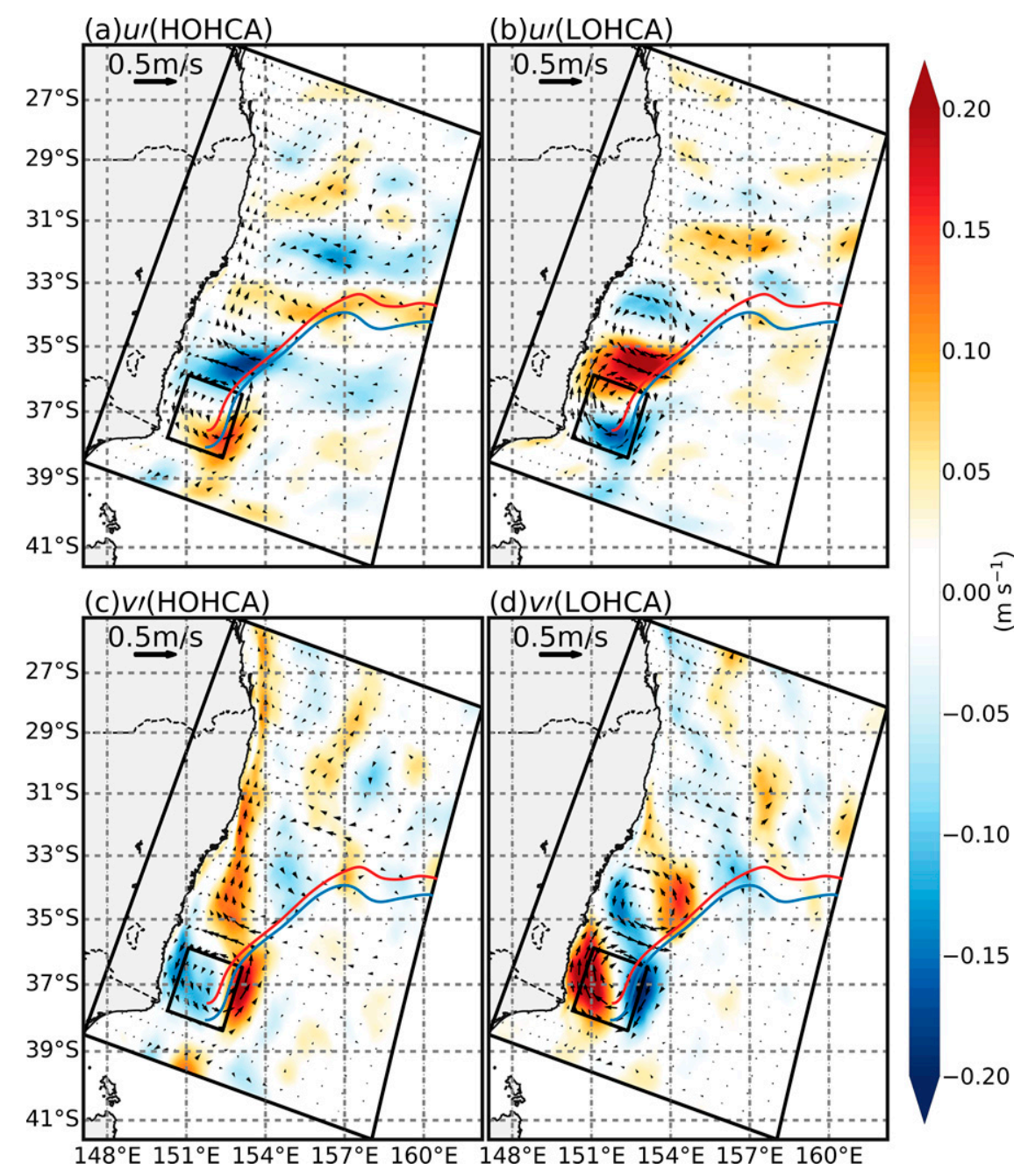

FIG. 7. Composite eastward surface velocity anomalies for the (a) high-OHC periods and (b) low-OHC periods. (c),(d) As in (a) and (b), but for the composite northward surface velocity anomalies. Blue line (red line) indicates the mean SSH contour of $0.3 \mathrm{~m}(0.35 \mathrm{~m})$. Black vectors indicate the surface velocity anomalies.

nonuniform with latitudes (Malan et al. 2021). Using a multidecadal ocean simulation, we characterized the spatial warming trends in the EAC, revealing cooling and warming trends equatorward and poleward of $33^{\circ} \mathrm{S}$, respectively (Fig. 1a). The pattern is associated with a decreasing (increasing) trend in poleward transport upstream (downstream) of $35^{\circ} \mathrm{S}$ (Fig. 6j). The transport at $28^{\circ} \mathrm{S}$ is significantly anticorrelated with the OHC2000 in the Tasman OHC box (Fig. 6e), and modulates the OHC2000 variability downstream. The decreasing trend in transport north of $35^{\circ} \mathrm{S}$ results from the poleward shift of the EAC system, which is projected to continue in the future (Oliver and Holbrook 2014; Bull et al. 2020), implying that the nonuniform warming trends in the EAC are likely to persist under continued global warming.

The frequency, duration, and intensity of MHWs in the global ocean have increased over the past century (Oliver et al. 2018) and are projected to continue to increase (Oliver et al. 2019). Compared to sea surface temperature, which can be highly affected by atmospheric variability, OHC2000 shows lower variability and an enhanced skill in predicting MHWs (Behrens et al. 2019). Here we show that OHC2000 variability in the Tasman OHC box is associated with eddy activity (Fig. 5a), particularly the occurrence and latitude of an anticyclonic eddy shedding when the EAC separates from the coast driven by barotropic instabilities. This implies that mesoscale eddies play an important role in driving ocean warming and MHWs in the EAC southern extension, consistent with the results of Elzahaby et al. (2021) showing advection dominated MHWs in this region. Eddy-rich WBC extension regions have high MHW intensity and greater complexity (Oliver et al. 2021); however, climate models disagree with observations in simulating MHWs in these regions due to their coarser resolution, and therefore higher resolution is required to capture this MHW variability (Pilo et al. 2019; 


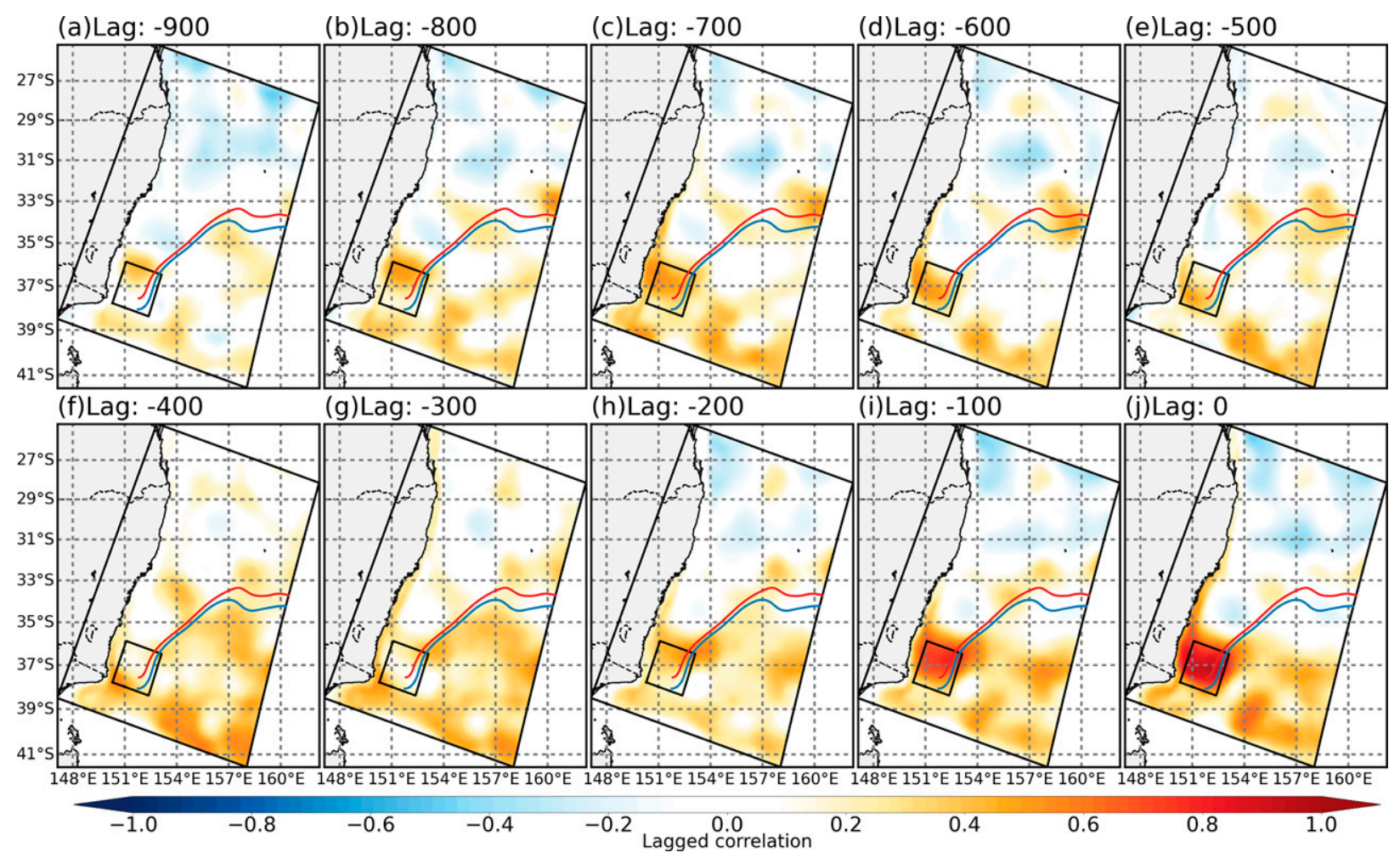

FIG. 8. Spatial distributions of the lagged correlation coefficients between the 1-yr low-pass filtered SLA and the OHC2000 index from (a) -900 to (j) 0 days. All correlation coefficients are statistically significant above the $95 \%$ confidence level. Blue line (red line) indicates the mean SSH contour of $0.3 \mathrm{~m}(0.35 \mathrm{~m})$.

Hayashida et al. 2020). Our results suggest that models that can resolve mesoscale processes such as eddy shedding are required to better represent MHWs and understand their physical drivers, as proposed by Pilo et al. (2019) and Hayashida et al. (2020). EKE in WBCs and their eddy-rich extensions have increased over the past three decades (MartínezMoreno et al. 2021). Our high-resolution $(<6 \mathrm{~km})$ ocean model results show statistically significant nonuniform EKE trends in the EAC system (Fig. 1c), which are consistent with satellite observations (Martínez-Moreno et al. 2021). Our results further highlighted that transport $\sim 880 \mathrm{~km}$ upstream is associated with the formation of anticyclonic eddies through barotropic instabilities in the Tasman Sea (Fig. 5). The EAC jet is more likely to separate and shed anticyclonic eddies around the Tasman OHC box when the poleward transport upstream is weak, while its separation latitude retracts northward when the transport upstream is stronger (Figs. 6a-d,f-i). The decreasing transport trends (Fig. 6j) appear to increase eddy activity and further result in ocean warming in the Tasman OHC box. Our findings reveal the dynamical mechanisms of eddy-induced warming due to the poleward shift of the EAC. These results can potentially be used to investigate warming in other Southern Hemisphere WBCs, such as the Brazil and Agulhas Currents.

We demonstrated that Rossby waves propagate into the model domain around $32^{\circ}-34^{\circ} \mathrm{S}$ and then turn southward at $157^{\circ} \mathrm{E}$ to propagate into the Tasman $\mathrm{OHC}$ box along the dynamical barrier of the EAC return flow (Fig. 8). Westward propagation of downwelling Rossby waves and a weaker upstream transport will increase the OHC2000 in the Tasman OHC box, but a stronger upstream transport together with upwelling Rossby waves tend to decrease the OHC2000, implying an asymmetric response to Rossby waves for the OHC2000 in the Tasman OHC box. It has been suggested that due to the contribution from Rossby waves in modulating the EAC extension transport, SLA to the east (around New Zealand) could be a useful predictor of western Tasman Sea MHWs (Li et al. 2020). Our findings build on Li et al. (2020) by demonstrating that both upstream transport and Rossby waves play an important role in modulating the OHC2000 variability in the Tasman Sea. In the Kuroshio Extension system (Japan), the arrival of Rossby waves at the western boundary leads to the acceleration of the Kuroshio Extension by enhancing the potential vorticity gradient (Taguchi et al. 2005). Therefore, an in-depth analysis of the dynamics and interactions between the EAC and Rossby waves is needed to study the potential predictability of MHWs in the future.

Although our time series covers only 22 years, there appears to be some evidence of decadal variability in our OHC and SLA results (Fig. 5a), which may be driven by climate modes and other large-scale natural variability. As discussed in previous studies (Sasaki et al. 2008; Holbrook et al. 2011), the SLA variability in the Tasman Sea is influenced by decadal El Niño-Southern Oscillation (ENSO) variability and 
(a)Transport $\left(28^{\circ} \mathrm{S}\right)$

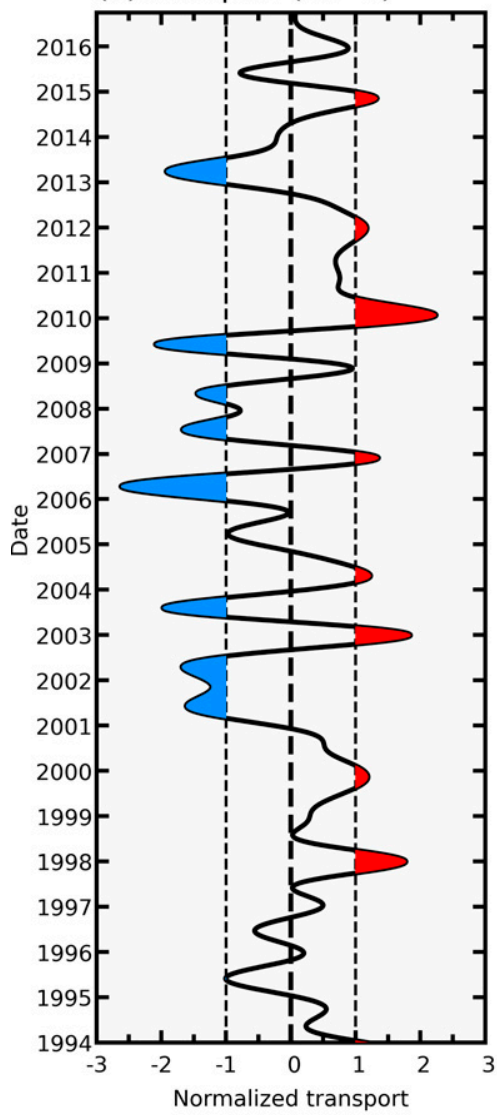

Normalized transport
(b)SLA

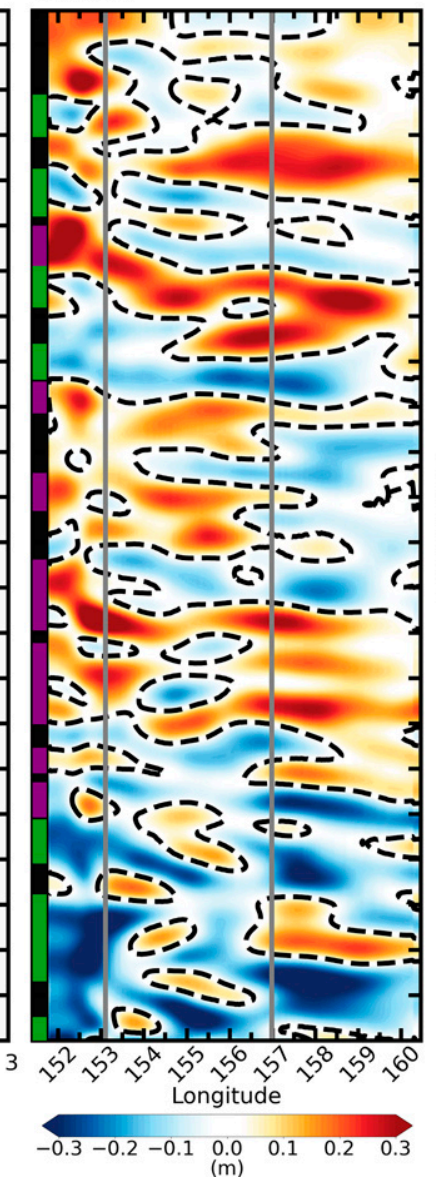

(c) Lagged correlation

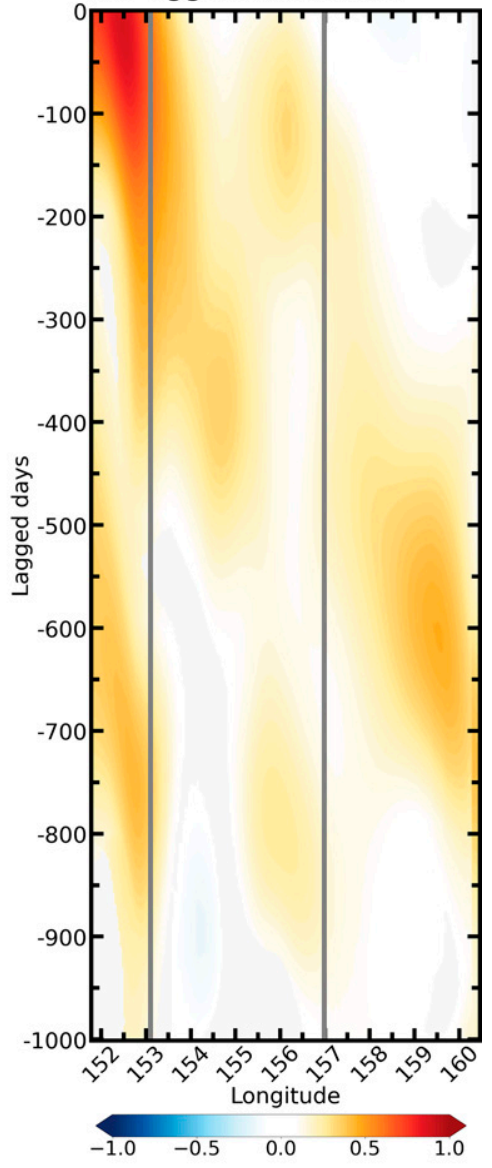

FIG. 9. (a) Time series of the 1-yr low-pass filtered poleward volume transport at $28^{\circ} \mathrm{S}$, with the linear trends removed and normalized by its STD. Periods when transport is larger (smaller) than 1.0 STD are highlighted in red (blue). (b) Hovmöller plot of the 1-yr low-pass filtered SLA along the SSH band. Gray lines indicate the longitudes of $157^{\circ} \mathrm{E}$ and the northeastern corner of the Tasman $\mathrm{OHC}$ box. Thick purple and green lines show the high-OHC and low-OHC periods, respectively. (c) Lagged correlations between the 1-yr low-pass filtered SLA and the OHC2000 index along the SSH band from -1000 to 0 days.

remotely forced Rossby waves. Using an eddy-resolving ocean model $\left(1 / 10^{\circ} \times 1 / 10^{\circ}\right)$, Sasaki et al. (2008) showed that the SLA variability in the Tasman Sea is connected to atmospheric variations over the central South Pacific associated with decadal ENSO. Remotely forced Rossby waves from the South Pacific Ocean, in response to decadal variations in ENSO, contribute to the variability in detrended sea level observations in Australia's Sydney Harbour and in EAC transport (Holbrook et al. 2011). In the present study, we use a high-resolution regional ocean model to capture the important processes of EAC separation and eddy formation, and the focus is on the internal variability in the EAC system. Our results clearly show how the EAC transport upstream and the westward propagating Rossby waves in the Tasman Sea influence the $\mathrm{OHC}$ variability in the EAC southern extension. External forcing from large-scale climate modes also plays an important role in EAC variability, which will be the focus of future work. Indeed, the understanding of the influence of the EAC on OHC gained from this study makes an important contribution toward understanding the influence of climate modes on the $\mathrm{OHC}$ in the EAC southern extension.

We have examined the drivers of $\mathrm{OHC}$ in the EAC and find that $\mathrm{OHC} 2000$ and SLA trends equatorward of $33^{\circ} \mathrm{S}$ and EKE trends in the EAC eastern extension are negative, but the OHC2000, SLA, and EKE trends are positive poleward of $33^{\circ} \mathrm{S}$. Moreover, we demonstrated that the OHC2000 and SLA variability in the EAC are driven by two mechanisms: an EAC mode and an eddy mode. The OHC2000 variability in the Tasman Sea is associated with the formation of anticyclonic eddies, which is modulated by 1) transport $\sim 880 \mathrm{~km}$ to the north and 2) the westward propagation of Rossby waves. When transport upstream is weak, the EAC jet is more stable and penetrates farther south. When this coincides 
(a) $\mathrm{HOHCA}$

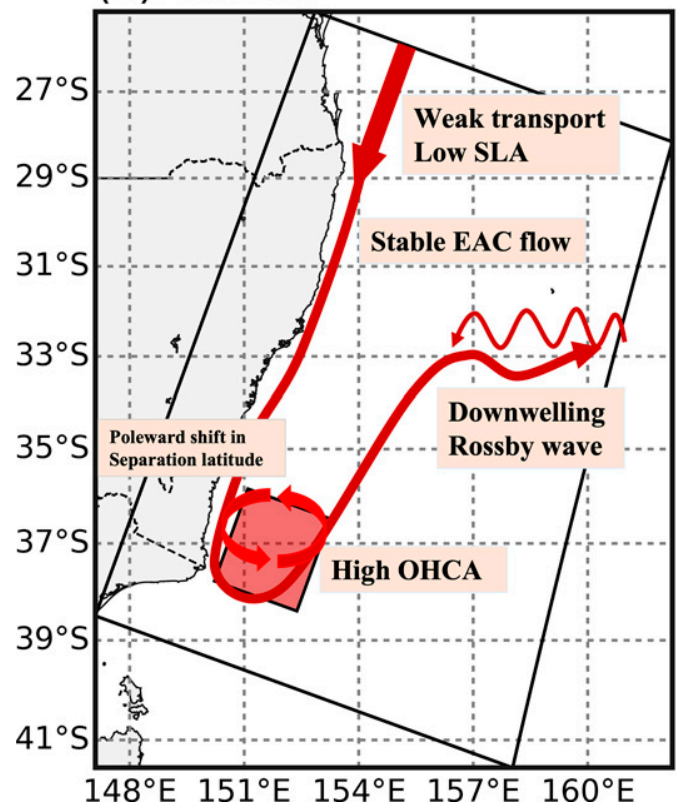

(b)LOHCA

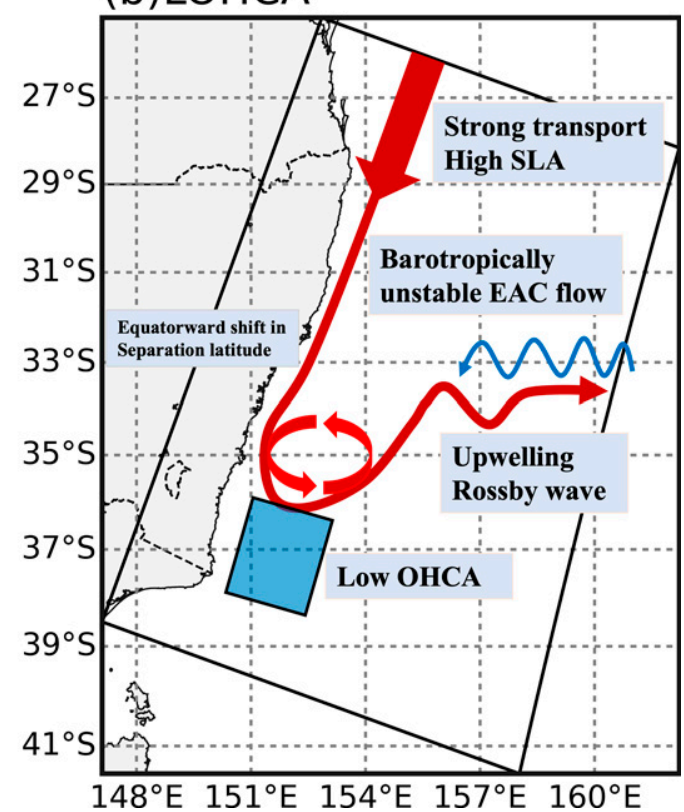

FIG. 10. Schematic diagram of the drivers of temperature extremes in the Tasman OHC box. (a) During highOHC periods, the upstream transport is weak associated with low SLA. The less unstable EAC penetrates farther south, and downwelling Rossby waves propagate positive SLA westward and pinch off anticyclonic eddies in the Tasman OHC Box. (b) During low-OHC periods, strong transport upstream associated with high SLA leads to a barotropically unstable EAC that separates north of the Tasman OHC box, and upwelling Rossby waves propagate negative SLA westward into the Tasman OHC box.

with downwelling Rossby waves that propagate positive SLA westward and pinch off anticyclonic eddies in the Tasman $\mathrm{OHC}$ box, OHC is a maximum in the EAC southern extension. On the other hand, strong transport upstream leads to a barotropically unstable EAC that separates farther to the north $\left(33.1^{\circ}-35.9^{\circ} \mathrm{S}\right)$. In addition, we identified that the EAC return flow acts as a dynamical barrier for the westward propagating Rossby waves, which then propagate SLA to the Tasman OHC box. Our findings shed new light on the mechanisms driving warming in the EAC southern extension, including the role of EAC transport and eddies. Our results have far-reaching implications for improving the potential predictability of MHWs in the EAC and WBCs more broadly.

Acknowledgments. This research is a contribution to the ARC Centre of Excellence for Climate Extremes, which is supported by the Australian Research Council via Grant CE170100023. The EAC-ROMS model development was partially supported by the Australian Research Council Grants DP140102337, LP160100162, and LP170100498. This research was undertaken with the assistance of resources and services from the National Computational Infrastructure (NCI), which is supported by the Australian Government. This research also includes computations using the computational cluster Katana (https://doi.org/10.26190/669X-A286), supported by Research Technology Services at UNSW Sydney.
Data availability statement. Model initial and boundary conditions were obtained from the Bluelink ReANalysis BRAN2016 (CSIRO Australia), available from https://research.csiro.au/ bluelink/outputs/data-access/. The atmospheric forcing was obtained from the Bureau of Meteorology Atmospheric high-resolution Regional Reanalysis for Australia (BARRA-R), available from http:/www.bom.gov.au/research/projects/reanalysis/. The tide forcing can be accessed at https://www.tpxo.net/ global/tpxo8-atlas. The model output used here (https://doi. org/10.26190/TT1Q-NP46) is available at https://researchdata. edu.au/high-resolution-22-version-20/1676421 (Li et al. 2021a).

\section{REFERENCES}

Beal, L. M., and S. Elipot, 2016: Broadening not strengthening of the Agulhas Current since the early 1990s. Nature, 540, 570 573, https://doi.org/10.1038/nature19853.

— , and Coauthors, 2011: On the role of the Agulhas system in ocean circulation and climate. Nature, 472, 429-436, https:// doi.org/10.1038/nature09983.

Behrens, E., D. Fernandez, and P. Sutton, 2019: Meridional oceanic heat transport influences marine heatwaves in the Tasman Sea on interannual to decadal timescales. Front. Mar. Sci., 6, 228, https://doi.org/10.3389/fmars.2019.00228.

Bowen, M. M., J. L. Wilkin, and W. J. Emery, 2005: Variability and forcing of the East Australian Current. J. Geophys. Res., 110, C03019, https://doi.org/10.1029/2004JC002533. 
Bull, C. Y., A. E. Kiss, A. Sen Gupta, N. C. Jourdain, D. Argúeso, A. Di Luca, and G. Sérazin, 2020: Regional versus remote atmosphere-ocean drivers of the rapid projected intensification of the East Australian Current. J. Geophys. Res. Oceans, 125, e2019JC015889, https://doi.org/10.1029/ 2019JC015889.

Cai, W., 2006: Antarctic ozone depletion causes an intensification of the Southern Ocean super-gyre circulation. Geophys. Res. Lett., 33, L03712, https://doi.org/10.1029/2005GL024911.

—, G. Shi, T. Cowan, D. Bi, and J. Ribbe, 2005: The response of the southern annular mode, the East Australian Current, and the southern mid-latitude ocean circulation to global warming. Geophys. Res. Lett., 32, L23706, https://oi.org/10. 1029/2005GL024701.

Cazenave, A., and Coauthors, 2018: Global sea-level budget 1993-present. Earth Syst. Sci. Data, 10, 1551-1590, https://doi. org/10.5194/essd-10-1551-2018.

Chapman, D. C., 1985: Numerical treatment of cross-shelf open boundaries in a barotropic coastal ocean model. $J$. Phys. Oceanogr., 15, 1060-1075, https://doi.org/10.1175/ 1520-0485(1985)015<1060:NTOCSO > 2.0.CO;2.

Cheng, L., K. E. Trenberth, J. Fasullo, T. Boyer, J. Abraham, and J. Zhu, 2017: Improved estimates of ocean heat content from 1960 to 2015. Sci. Adv., 3, e1601545, https://doi.org/10.1126/ sciadv. 1601545 .

— , and Coauthors, 2020: Record-setting ocean warmth continued in 2019. Adv. Atmos. Sci., 37, 137-142, https://doi.org/10. 1007/s00376-020-9283-7.

Egbert, G. D., and S. Y. Erofeeva, 2002: Efficient inverse modeling of barotropic ocean tides. J. Atmos. Oceanic Technol., 19, 183-204, https://doi.org/10.1175/1520-0426(2002)019<0183: EIMOBO $>2.0 . \mathrm{CO} ; 2$.

Elzahaby, Y., A. Schaeffer, M. Roughan, and S. Delaux, 2021: Oceanic circulation drives the deepest and longest marine heatwaves in the East Australian Current system. Geophys. Res. Lett., 48, e2021GL094785, https://doi.org/10.1029/ 2021 GL094785.

Everett, J. D., M. E. Baird, P. R. Oke, and I. M. Suthers, 2012: An avenue of eddies: Quantifying the biophysical properties of mesoscale eddies in the Tasman Sea. Geophys. Res. Lett., 39, L16608, https://doi.org/10.1029/2012GL053091.

Flather, R. A., 1976: A tidal model of the north-west European continental shelf. Mem. Soc. Roy. Sci. Liege, 6, 141-164.

Godfrey, J. S., G. R. Cresswell, T. J. Golding, A. F. Pearce, and R. Boyd, 1980: The separation of the East Australian Current. J. Phys. Oceanogr., 10, 430-440, https://doi.org/10.1175/ 1520-0485(1980)010<0430:TSOTEA > 2.0.CO;2.

Hayashida, H., R. Matear, P. Strutton, and X. Zhang, 2020: Insights into projected changes in marine heatwaves from a high-resolution ocean circulation model. Nat. Commun., 11, 4352, https://doi.org/10.1038/s41467-020-18241-x.

Hill, K. L., S. R. Rintoul, P. R. Oke, and K. Ridgway, 2010: Rapid response of the East Australian Current to remote wind forcing: The role of barotropic-baroclinic interactions. J. Mar. Res., 68, 413-431, https://doi.org/10.1357/002224010794657218.

Holbrook, N. J., I. D. Goodwin, S. McGregor, E. Molina, and S. B. Power, 2011: ENSO to multi-decadal time scale changes in East Australian Current transports and Fort Denison sea level: Oceanic Rossby waves as the connecting mechanism. Deep-Sea Res. II, 58, 547-558, https://doi.org/10.1016/j.dsr2. 2010.06.007.
Hu, D., and Coauthors, 2015: Pacific western boundary currents and their roles in climate. Nature, 522, 299-308, https://doi. org/10.1038/nature14504.

Kang, D., and E. N. Curchitser, 2015: Energetics of eddy-mean flow interactions in the Gulf Stream region. J. Phys. Oceanogr., 45, 1103-1120, https://doi.org/10.1175/JPO-D-14-0200.1.

Kerry, C., and M. Roughan, 2020: Downstream evolution of the East Australian Current system: Mean flow, seasonal, and intra-annual variability. J. Geophys. Res. Oceans, 125, e2019JC015227, https://doi.org/10.1029/2019JC015227.

- B. Powell, M. Roughan, and P. Oke, 2016: Development and evaluation of a high-resolution reanalysis of the East Australian Current region using the Regional Ocean Model System (ROMS 3.4) and Incremental Strong-Constraint 4Dimensional Variational (IS4D-Var) data assimilation. Geosci. Model Dev., 9, 3779-3801, https://doi.org/10.5194/gmd-93779-2016.

—, M. Roughan, and B. S. Powell, 2018: Observation impact in a regional reanalysis of the East Australian Current system. J. Geophys. Res. Oceans, 123, 7511-7528, https://doi.org/10. 1029/2017JC013685.

Li, Jianping, C. Sun, and F.-F. Jin, 2013: NAO implicated as a predictor of Northern Hemisphere mean temperature multidecadal variability. Geophys. Res. Lett., 40, 5497-5502, https://doi. org/10.1002/2013GL057877.

Li, Junde, C. Kerry, and M. Roughan, 2021a: A high-resolution, 22-year, free-running, hydrodynamic simulation of the East Australia Current system using the regional ocean modeling system (version 2.0). University of New South Wales, accessed 2021, https://doi.org/10.26190/TT1Q-NP46.

$[,-\longrightarrow$, and $-2021 \mathrm{~b}$ : Dynamics of interannual eddy kinetic energy modulations in a western boundary current. Geophys. Res. Lett., 48, e2021GL094115, https://doi.org/10. 1029/2021GL094115.

Li, Z., N. J. Holbrook, X. Zhang, E. C. J. Oliver, and E. A. Cougnon, 2020: Remote forcing of Tasman Sea marine heatwaves. J. Climate, 33, 5337-5354, https://doi.org/10.1175/JCLI-D-190641.1.

Lu, J., and Q. Liu, 2013: Gap-leaping Kuroshio and blocking westward-propagating Rossby wave and eddy in the Luzon Strait. J. Geophys. Res. Oceans, 118, 1170-1181, https://doi.org/10. 1002/jgrc.20116.

Malan, N., M. Roughan, and C. Kerry, 2021: The rate of coastal temperature rise adjacent to a warming western boundary current is nonuniform with latitude. Geophys. Res. Lett., $\mathbf{4 8}$, e2020GL090751, https://doi.org/10.1029/2020GL090751.

Marchesiello, P., and J. H. Middleton, 2000: Modeling the East Australian Current in the western Tasman Sea. J. Phys. Oceanogr., 30, 2956-2971, https://doi.org/10.1175/1520-0485(2001)031<2956: MTEACI $>2.0 . \mathrm{CO} ; 2$.

Martínez-Moreno, J., A. M. Hogg, M. H. England, N. C. Constantinou, A. E. Kiss, and A. K. Morrison, 2021: Global changes in oceanic mesoscale currents over the satellite altimetry record. Nat. Climate Change, 11, 397-403, https://doi.org/10. 1038/s41558-021-01006-9.

Matear, R. J., M. A. Chamberlain, C. Sun, and M. Feng, 2013: Climate change projection of the Tasman Sea from an eddyresolving ocean model. J. Geophys. Res. Oceans, 118, 29612976, https://doi.org/10.1002/jgrc.20202.

Mellor, G. L., and T. Yamada, 1982: Development of a turbulence closure model for geophysical fluid problems. Rev. Geophys., 20, 851-875, https://doi.org/10.1029/RG020i004p00851. 
Nilsson, C. S., and G. R. Cresswell, 1980: The formation and evolution of East Australian Current warm-core eddies. Prog. Oceanogr., 9, 133-183, https://doi.org/10.1016/00796611(80)90008-7.

Oke, P. R., G. B. Brassington, D. A. Griffin, and A. Schiller, 2008: The Bluelink Ocean Data Assimilation System (BODAS). Ocean Modell., 21, 46-70, https://doi.org/10.1016/j.ocemod.2007. 11.002 .

— , and Coauthors, 2013: Towards a dynamically balanced eddy-resolving ocean reanalysis: BRAN3. Ocean Modell., 67, 52-70, https://doi.org/10.1016/j.ocemod.2013.03.008.

—, G. S. Pilo, K. Ridgway, A. Kiss, and T. Rykova, 2019: A search for the Tasman front. J. Mar. Syst., 199, 103217, https://doi.org/10.1016/j.jmarsys.2019.103217.

Oliver, E. C. J., and N. J. Holbrook, 2014: Extending our understanding of South Pacific gyre "spin-up": Modeling the East Australian Current in a future climate. J. Geophys. Res. Oceans, 119, 2788-2805, https://doi.org/10.1002/2013JC009591.

—, T. J. O'Kane, and N. J. Holbrook, 2015: Projected changes to Tasman Sea eddies in a future climate. J. Geophys. Res. Oceans, 120, 7150-7165, https://doi.org/10.1002/2015JC010993.

— , and Coauthors, 2018: Longer and more frequent marine heatwaves over the past century. Nat. Commun., 9, 1324, https://doi.org/10.1038/s41467-018-03732-9.

—, and Coauthors, 2019: Projected marine heatwaves in the 21st century and the potential for ecological impact. Front. Mar. Sci., 6, 734, https://doi.org/10.3389/fmars.2019.00734.

—, J. A. Benthuysen, S. Darmaraki, M. G. Donat, A. J. Hobday, N. J. Holbrook, R. W. Schlegel, and A. Sen Gupta, 2021: Marine heatwaves. Annu. Rev. Mar. Sci., 13, 313-342, https://doi.org/10.1146/annurev-marine-032720-095144.

Pilo, G. S., N. J. Holbrook, A. E. Kiss, and A. M. Hogg, 2019: Sensitivity of marine heatwave metrics to ocean model resolution. Geophys. Res. Lett., 46, 14604-14612, https://doi.org/ 10.1029/2019GL084928.

Qiu, B., and S. Chen, 2006: Decadal variability in the large-scale sea surface height field of the South Pacific Ocean: Observations and causes. J. Phys. Oceanogr., 36, 1751-1762, https:// doi.org/10.1175/JPO2943.1.

Qu, T., I. Fukumori, and R. A. Fine, 2019: Spin-up of the Southern Hemisphere super gyre. J. Geophys. Res. Oceans, 124, 154-170, https://doi.org/10.1029/2018JC014391.

Ridgway, K. R., 2007: Long-term trend and decadal variability of the southward penetration of the East Australian Current. Geophys. Res. Lett., 34, L13613, https://doi.org/10.1029/ 2007 GL030393.

Ryan, S., C. C. Ummenhofer, G. Gawarkiewicz, P. Wagner, M. Scheinert, A. Biastoch, and C. W. Böning, 2021: Depth structure of Ningaloo Niño/Niña events and associated drivers.
J. Climate, 34, 1767-1788, https://doi.org/10.1175/JCLI-D-191020.1.

Sasaki, Y. N., S. Minobe, N. Schneider, T. Kagimoto, M. Nonaka, and H. Sasaki, 2008: Decadal sea level variability in the South Pacific in a global eddy-resolving ocean model hindcast. J. Phys. Oceanogr., 38, 1731-1747, https://doi.org/10.1175/ 2007JPO3915.1.

Shchepetkin, A. F., and J. C. McWilliams, 2005: The Regional Oceanic Modeling System (ROMS): A split-explicit, free-surface, topography-following-coordinate oceanic model. Ocean Modell., 9, 347-404, https://doi.org/10.1016/j.ocemod.2004.08. 002.

Sloyan, B. M., and T. J. O'Kane, 2015: Drivers of decadal variability in the Tasman Sea. J. Geophys. Res. Oceans, 120, 31933210, https://doi.org/10.1002/2014JC010550.

Su, C.-H., and Coauthors, 2019: BARRA v1.0: The Bureau of Meteorology atmospheric high-resolution regional reanalysis for Australia. Geosci. Model Dev., 12, 2049-2068, https://doi. org/10.5194/gmd-12-2049-2019.

Taguchi, B., S. Xie, H. Mitsudera, and A. Kubokawa, 2005: Response of the Kuroshio Extension to Rossby waves associated with the 1970s climate regime shift in a high-resolution ocean model. J. Climate, 18, 2979-2995, https://doi.org/10. 1175/JCLI3449.1.

von Schuckmann, K., and Coauthors, 2016: An imperative to monitor Earth's energy imbalance. Nat. Climate Change, 6, 138-144, https://doi.org/10.1038/nclimate2876.

— , and Coauthors, 2020: Heat stored in the Earth system: Where does the energy go?Earth Syst. Sci. Data, 12, 20132041, https://doi.org/10.5194/essd-12-2013-2020.

Whiteway, T. G., 2009: Australian bathymetry and topography grid, June 2009. Geoscience Australia Record 2009/21, 46 pp., https://data.gov.au/data/dataset/australian-bathymetry-andtopography-grid-june-2009.

Wu, L., and Coauthors, 2012: Enhanced warming over the global subtropical western boundary currents. Nat. Climate Change, 2, 161-166, https://doi.org/10.1038/nclimate1353.

Yang, H., G. Lohmann, W. Wei, M. Dima, M. Ionita, and J. Liu, 2016: Intensification and poleward shift of subtropical western boundary currents in a warming climate. J. Geophys. Res. Oceans, 121, 4928-4945, https://doi.org/10.1002/2015JC011513.

— , and Coauthors, 2020: Poleward shift of the major ocean gyres detected in a warming climate. Geophys. Res. Lett., 47, e2019GL085868, https://doi.org/10.1029/2019GL085868.

Yue, S., and C. Wang, 2004: The Mann-Kendall test modified by effective sample size to detect trend in serially correlated hydrological series. Water Resour. Manage., 18, 201-218, https://doi.org/10.1023/b:warm.0000043140.61082.60. 